\title{
Bariatric surgery in a national cohort of women: sociodemographics and obstetric outcomes
}

Ann Josefsson, Marie Blomberg, Marie Bladh, Sven G Frederiksen and Gunilla Sydsjö

\section{Linköping University Post Print}

N.B.: When citing this work, cite the original article.

Original Publication:

Ann Josefsson, Marie Blomberg, Marie Bladh, Sven G Frederiksen and Gunilla Sydsjö, Bariatric surgery in a national cohort of women: sociodemographics and obstetric outcomes, 2011, American Journal of Obstetrics and Gynecology, (205), 3, 25.

http://dx.doi.org/10.1016/j.ajog.2011.03.025

Copyright: Elsevier http://www.elsevier.com/

Postprint available at: Linköping University Electronic Press

http://urn.kb.se/resolve?urn=urn:nbn:se:liu:diva-70737 
Bariatric surgery in a national cohort of women: sociodemographics and obstetric outcomes

Ann JOSEFSSON, MD, PhD*, Marie BLOMBERG, MD, PhD*, Marie BLADH, MA*, Sven G FREDERIKSEN, MD**, Gunilla SYDSJÖ, PhD*

*Division of Obstetrics and Gynaecology, Department of Molecular and Clinical Medicine Faculty of Health Sciences, Linköping University, Sweden

** Department of Surgery, Lund University Hospital, Lund, Sweden

Correspondence/Reprint requests: Ann Josefsson

Division of Obstetrics and Gynaecology, Department of Molecular and Clinical Medicine Faculty of Health Sciences

Linköping University

SE - 58185 Linköping, Sweden

Tel: +4610103 31 82; fax: +4613148156

e-mail: ann.josefsson@lio.se

\section{Word count}

Abstract: 144 words

Text: 3255 words 
Article condensation: Preconception bariatric surgery in obese women may be associated with improved obstetrical outcomes.

Short version of title: Bariatric surgery in a national cohort of women 
Abstract:

Objectives: In a large prospective Swedish national cohort we investigated individual birth characteristics for women who had undergone bariatric surgery and their obstetric outcome and made comparisons with all other women during the same period.

Study Design: The cohort consisted of 494,692 women born 1973 - 1983 of which 681 women who had undergone bariatric surgery constituted the index group.

Results: The index women more often have parents with lower sociodemographic status and are more often born LGA. The women surgically treated before their first child had a shorter gestational length, their children had lower birth weight and were more often born SGA compared to the children born to the reference mothers. Women whose child was born prior to their bariatric surgery more often had a cesarean section, and their children were more often LGA.

Conclusion: Preconception bariatric surgery in obese women may be associated with improved obstetrical outcomes.

Authors: Ann JOSEFSSON, Marie BLOMBERG, Marie BLADH, Sven G FREDERIKSEN, Gunilla SYDSJÖ

Key words: Bariatric surgery; Obesity; Pregnancy; Delivery 


\section{Introduction}

Obesity has reached epidemic proportions globally, with at least 300 million adults clinically obese according to the World Health Organization. Obesity is a major contributor to the global burden of chronic disease and disability. An increasing number of women and female adolescents suffer from obesity today both in the Western world and in developing countries. Obese women are more often afflicted with gestational hypertension and gestational diabetes $(1,2)$. There is an increased risk of birth defects in the offspring of obese mothers, most pronounced for neural tube defects, congenital heart defects and orofacial clefts (3). A number of threatening complications during pregnancy for both the mother and the infant occur more often among obese women (4).

Obesity is known to lessen quality of life, and in all likelihood has done so before it was recognized as a social and medical problem. Voluntary weight-loss by dieting is effective in the short perspective, and is the mainstay of treatment, whether "self-administered" or under professional supervision. Long-term efficacy of dieting is disappointing, and the same, regrettably, holds true for pharmacological treatment as an adjunct $(5,6)$. In the last few decades, effective treatment has become available by surgical means. Early surgical methods were flawed by side effects, and some later methods could indeed diminish these effects, at the price of not so successful weight loss. The most widely used method today, gastric bypass, seems to strike an attractive balance between good long-term weight loss and acceptable side effects $(6,7)$. This balance, as well as the feasibility of this operation laparoscopically, has resulted in a rapidly growing number of patients undergoing gastric bypass. Among these are many fertile women, most centers report $80 \%$ of patients undergoing obesity surgery are female.

There are several studies that have evaluated obstetric outcome after bariatric surgery (8-13). Overall it seems as if both pregnancy and delivery complications are reduced after surgery but 
the studies differ in design as well as how the control groups are chosen (14). Some studies compare outcome between women who underwent surgery to obese controls (15), others use control subjects stratified by Body Mass Index (BMI) (16).

Swedish population-based registers are prospectively collected and contain well validated data. They therefore provide a unique opportunity to study sociodemographic background factors and reproductive pattern.

The objective of this study with a large prospective cohort from Swedish medical health registries was twofold. Firstly, the individual birth characteristics for women who had undergone bariatric surgery were compared with all other women in the cohort during the study period. Secondly, the obstetric outcome was assessed among women delivering their first child after or before bariatric surgery compared to all other women during the same period, after suitable adjustments. 


\section{Material and methods}

Women born between 1973 and 1983 were chosen as study cohort, since bariatric surgery commenced in the late eighties in Sweden in its modern form. The oldest women in our cohort would then have been in their late teens, and thus eligible for bariatric surgery. The limit to 1983 was chosen so as not to include too many women who had not yet given birth. The index groups were thus women born between 1973 and 1983, having undergone surgery to attain weight loss, either before or after delivery of their first child. All women born in the same time span served as reference group.

Socio-economic data for the parents to the studied women was recorded, as well as characteristics related to the women's own birth in 1973 to 1983 . We then collected socioeconomic data, as well as health related factors such as body mass index (BMI), diabetes, hypertension/preeclampsia and smoking prevalence at the time of the studied women's own first pregnancy. Finally, obstetric outcome of the study cohorts first childbirth were recorded. The Swedish Medical Birth Register (MBR) was established in 1973 and covers approximately $99 \%$ of all births. The register contains information on birth outcomes as well as certain maternal characteristics (17). Almost all pregnant women in Sweden regularly visit antenatal clinics, usually from the $6-9^{\text {th }}$ week of gestation; from these records several data such as pre-gestational weight, BMI and smoking habits can be retrieved. The Total Population Register (TPR) contains information on births, deaths, marital status, as well as information on migrations, and country of origin for Swedish residents born abroad (18). The National Patient Register (NPR) has been in use since 1964 and from 1987 and onwards it covers all in-patient care in Sweden (19). The diagnoses in the NPR are based on the Swedish version of the World Health Organization international classification of diseases (ICD). ICD-8 (20) was used until 1986, ICD-9 (21) was used between 1987 and 1996, and ICD-10 (22) from 1997 and onwards. The Causes of Death Register records information on 
all deceased persons registered in Sweden at the time of death (23), and, by use of the MultiGeneration Register it is possible to identify the fathers of the children registered in the MBR and the TPR (24). Information on the educational level of the women in the study population as well as their parents was retrieved by means of the Education Register and the Population and Housing Census 1970, respectively $(25,26)$.

All women born in 1973 - 1983 according to the MBR and the TPR, who were alive and still living in Sweden at 13 years of age, served as the study population $(n=500,245)$. Women with missing values on birth weight and/or gestational length were excluded $(n=3360)$, as were those with extremely high or low birth weights relative to their length of gestation (2193 women). The final cohort therefore consisted of 494,692 women who were followed up until the end of year 2006. During the study period, $4.3 \%$ of the women emigrated and $0.38 \%$ were deceased. The 494,692 women were then individually linked to the maternal personal identification numbers for births occurring in the MBR before the year of 2006 (the first birth occurred in 1987). At the time of the study the women were 23 - 33 years old, with maximum maternal age thus 33 years. In the Swedish population, mean age at first child-bearing is 29.8 years and a large proportion of our study population is still to experience their first pregnancy. A total of 189,819 mother-firstborn-offspring pairs were identified, of which 912 pairs were excluded due to missing values on the child's birth weight and/or gestational length and an additional 40 due to the children having extremely high birth weights compared to the length of gestation. Thus, 188,867 mother-firstborn-offspring pairs were available for analysis. Bariatric surgery was defined as women having had gastroplasty, gastric banding or gastric bypass, whether performed with laparoscopic or open technique. These formed the vast majority of patients, singular cases were identified with other methods such as intragastric balloon or duodenal shunt with biliopancreatic diversion, none of these were included in the analysis as they were too few and there is also some uncertainty about the coding for these 
procedures. The information on the operated women was retrieved from the NPR. Information on socioeconomic and other background characteristics of both the studied women and their parents was retrieved from the registries above. On the parents we had information on their educational levels in 1985, their country of origin, as well as the mothers' marital status, parity, and age at the time of giving birth (i.e. 1973-83). For the women we had information on several birth-related variables such as birth weight, gestational length, instrumental delivery, cesarean section, as well as if the women were the result of a twin birth. Preterm birth was defined as less than 37 completed weeks of gestation, small for gestational age (SGA) was defined as a birth weight less than 2 standard deviations below the mean birth weight and large for gestational age was defined as a birth weight more than 2 standard deviations according to Swedish external standards from 1996 (27). Normal delivery was defined as a vaginal delivery without any instrumental assistance. Furthermore, we were able to retrieve information on the women's educational levels and marital status at the time of giving birth. For the women who became mothers during the study period we also had information on cohabitation status, body mass index (BMI) and smoking habits during early pregnancy, as well as age when giving birth.

\section{Statistical Analyses}

Women who had undergone surgery to attain weight loss were compared to all women born in the same time span by means of the $\chi^{2}-$ test and the $t$-test.

The data were also modeled through Cox's proportional hazards model to estimate the effect of bariatric surgery on the women's subsequent likelihood of giving birth. The timedimension was defined as age and subjects exited from risk when they gave birth to the first child, emigrated for the first time, died, or reached the end of follow-up, whichever took place first. Both crude and adjusted hazard ratios (HR) and corresponding 95\% confidence intervals (CI) were calculated. Adjustments were made for parental socioeconomic characteristics. In 
addition to the $\chi^{2}$ - tests presented in Tables 2 and 4, differences between the women who had undergone bariatric surgery and those who had not, were estimated by means of multiple logistic regression analysis, controlling for the background variables presented in Tables 1 and 3, and the odds ratios (OR) and corresponding confidence intervals (CI) were calculated. By using this method we were able to simultaneously account for the combined effect of the studied variables. However, as the differences between these analyses and the $\chi^{2}-$ tests presented in the tables are not substantial; we chose not to present the results of these additional analyses.

This study was approved by the Human Research Ethics Committee; Faculty of Health Sciences, Linköping University. 


\section{Results}

A total of 681 women were identified as having undergone bariatric surgery. Two hundred and forty-one women had their surgery after delivery of their first child and 126 women had surgery performed before the first child was born. The remaining 314 women had no childbirths during the study period. Mean time between the primary bariatric surgery and delivery of first child was slightly more than 4 years (mean $=4.22$ and $\mathrm{SD}=3.51$ ). Out of the 126 women who had surgery performed before the first child was born, 9 women had a new bariatric procedure after their delivery. The second bariatric surgical procedure was performed within a time span of 6 months and six years after the delivery of their first child.

Sociodemographic characteristics of the parents to all women in the study cohort $(\mathrm{n}=$ 494,692) and the women who had undergone bariatric surgery, the index group $(n=681)$ and their own birth characteristics are presented in table 1 and 2. In short, women who had undergone surgery had mothers who were more often unmarried, were somewhat younger (mean difference 0.2 years) and had a lower level of education ( $p$-value $<0.001$ on all three variables) compared to those who had not undergone bariatric surgery. In analyzing their own birth characteristics, these women were also found to weigh slightly more at birth and were more often born large for gestational age (LGA), $\mathrm{p}=0.006$ and 0.004 respectively. These differences remained significant in a multivariate analysis including all variables in table 1 as independent variables (data not shown).

When the women themselves became pregnant, they were more likely to have a lower degree of education, were more seldom living together with the child's father and finally had a significantly higher BMI ( $\mathrm{p}=<0.001)$, table 3 . The women who had undergone surgery before their first child did not differ in mode of delivery from the reference group with no 
gastric surgery (table 4). However, women who had their bariatric surgery after the birth of their first child were more often delivered with a cesarean section. When analyzing the neonatal data of the firstborn child of women who had undergone surgery before pregnancy the children weighed significantly less, had a shorter gestational length and were more often SGA, table 4. The children of women who underwent bariatric surgery after their first delivery weighed significantly more compared to the first child of the women in the reference group as well as to those who had surgery before their first child $(p=0.030$ and 0.002 , respectively), table 4 . These differences remain significant in a multivariate analysis, controlling for all variables presented in table 3 (data not shown). The analyses further revealed that women who had had bariatric surgery did experience a higher birth rate compared to women who had not undergone surgery $(\mathrm{HR}=1.203$ and its corresponding $\mathrm{p}$ value <0.001). 


\section{Comment}

In this large prospective, national cohort study we found that Swedish women born 1973 1983 who have undergone bariatric surgery more often have parents with lower sociodemographic status and are more often born LGA. When these surgically corrected women themselves were giving birth to their first child they were also younger, less educated, more often smokers and more seldom living together with the child's father compared to all other women. Despite a surgical intervention in order to reduce weight, more than $50 \%$ of the women were still obese at the beginning of the pregnancy resulting in their first child. However, the percentage of morbidly obese women was smaller in this group compared to the women who had bariatric surgery after the birth of their first child. We also aimed to study the frequencies of hypertension/preeclampsia and diabetes during pregnancy but found no differences. This result is in accordance with earlier findings on pregnancy outcome after bariatric surgery $(9,28)$.

The obstetric outcome of the women surgically treated before their first child is interesting as they show a significantly shorter gestational length and as their children have a lower birth weight and are more often born SGA compared to the children born to mothers in the reference group. That is in accordance with what was stated in a recent review where the incidence of intrauterine growth restriction and SGA appeared to be increased after bariatric surgery (14), although there are contrary results in other studies. Australian data showed birth weights after laparoscopic adjustable gastric banding (LABG) consistent with normal community birth weights (9). Wax et al also found that birth weights were similar among women delivering after gastric bypass compared to women delivering without prior bariatric surgery (13). In a study from France low birth weight occurred even less often among women who underwent LABG but that was in comparison with obese women (15). One reason for contradicting results could be different compositions of the reference group. In a study by 
Patel the incidence of SGA after surgery was higher (11.5\%) compared with non obese patients but not significantly different from obese (2.6\%) and severely obese patients $(3.7 \%)$ (16).

Another difficulty comparing data from different studies is that the interval of time between surgery and child birth is not the same. Most bariatric surgeons recommend delaying pregnancy for at least $12-18$ months following the procedure $(14,29)$. These guidelines are meant to discourage women from becoming pregnant during the rapid weight loss phase of the first postsurgical year. Pregnancy during this time is suspected to increase the risk for a malnourished fetus and possibly resulting in children with low birth weight (10). But, there are no data validating this statement $(10,11)$. Wax et al concluded that obstetric and neonatal outcomes were similar in women conceiving during or after the period of maximal weight loss following gastric by pass surgery (30).

In the present study, there was no increased risk for giving birth preterm after bariatric surgery which might be explained by the fact that the mean time between surgery and delivery was around 4 years.

Mode of delivery for the women who have undergone bariatric surgery before the first child did not differ from the reference group which only somewhat confirms the results from other studies (14). The women who underwent bariatric surgery after their first child more often had a cesarean section, and their children were more often LGA. In this group of women 45 $\%$ already had a BMI of 35 or more at the birth of their first child in comparison with the group of surgically corrected women where around $28 \%$ were morbidly obese. Hence, although the majority of surgically treated women are still obese the degree of obesity has diminished significantly as well as the risks of giving birth to a LGA baby. From a generational perspective it seems as being born LGA is connected with obesity in women. 
Our findings suggest that surgical treatment before pregnancy might break the transmission of giving birth to LGA babies.

Unfortunately we have no information on weight gain during pregnancy due to too many missing weight measurements at the time of delivery or at the postnatal check-up but one can suspect that the weight after delivery has increased further (31). In case of obesity it is obviously beneficial to undergo gastric surgery before childbearing as it seems as a possible way to disrupt a negative pattern with babies born LGA and with complicated deliveries which in turn poses risks for the newly delivered mother.

One can speculate that fetal programming may be influenced through bariatric surgery and may also work to "extinguish" the generational link of obesity between mother and offspring through epigenetic influences.

There are always limitations in register studies and our study is no exception, for instance diagnoses on intercurrent diseases are usually not fully reliable. Although the quality of Swedish registers in general is good, the NPR includes errors that may have consequences for the results. In validation studies the errors on ICD-chapter levels were estimated to be $4 \%$ in 1990, however, there is no recent validation and possible errors on each surgical procedure in the register cannot be ignored. Therefore we have chosen to analyze the bariatric surgical procedures as one entity.

It is postulated that bariatric surgery diminishes the risk for diabetes and this is a hypothesis which needs to be investigated in a clinical study and maybe also with a longitudinal perspective. Another limitation is that the information on weight gain during pregnancy is lacking. It would be very interesting to find out whether there was a difference in pregnancy weight gain between the women who had undergone bariatric surgery before their first child compared to those who were operated after their first childbearing. 
This prospective study shows that mothers having undergone bariatric surgery have a lower risk for LGA babies. This is also an advantage for the children, at least in the short term. Whether it confers any long term advantages is uncertain. It would be highly interesting to follow the long-term weight and BMI evolution of the children to the operated mothers; the mothers are obviously so highly motivated to diminish their obesity that they have chosen to undergo major surgery - can their motivation be strong enough to hinder their offspring from becoming obese?

Finally, the ongoing concern about a theoretical risk of congenital malformations in the offspring of women after bariatric surgery (14) has not been addressed in this study as it needs a larger sample size.

To our knowledge this is the only study with a national cohort investigating prospectively collected data on sociodemographics and obstetric outcome for the women themselves having undergone bariatric surgery and for their preoperative or subsequent deliveries.

In conclusion, information from general practitioners as well as obstetricians to women in reproductive age with clinically severe obesity might include the potential benefits of bariatric surgery before pregnancy. 


\section{References}

1. Weiss JL, Malone FD, Emig D, et al. Obesity, obstetric complications and cesarean delivery rate--a population-based screening study. Am. J. Obstet. Gynecol. 2004; 190:1091-7..

2. Robinson HE, O’Connell CM, Joseph KS, McLeod NL. Maternal outcomes in pregnancies complicated by obesity. Obstet. Gynecol. 2005; 106: 1357-64.

3. Blomberg MI, Källén B. Maternal obesity and morbid obesity: The risk for birth defects in the offspring. Birth Defects Res A Clin Mol Teratol. 2010; 8:35.

4. Colquitt JL, Picot J, Loveman E, Clegg AJ. Surgery for obesity. Cochrane Database Syst Rev. 2009;(2): CD003641.

5. Jaunoo SS, Southall PJ. Bariatric surgery. Int J Surg 2010; 8:86-89.

6. Picot J, Jones J, Colquitt JL, Gospodarevskaya E, Loveman E, Baxter L, Clegg AJ. The clinical effectiveness and cost-effectiveness of bariatric (weight loss) surgery for obesity: a systematic review and economic evaluation. Health Technol Assess. 2009; 13: 1-190, 215-357, iii-iv.

7. Cedergren MI. Maternal morbid obesity and the risk of adverse pregnancy outcome. Obstet Gynecol 2004; 103:219-24.

8. Dao T, Kuhn J, Ehmer D, Fisher T, McCarty T. Pregnancy outcomes after gastric-bypass surgery. Am J Surg. 2006; 192:762-6.

9. Dixon JB, Dixon ME, O'Brien PE. Birth outcomes in obese women after laparoscopic adjustable gastric banding. Obstet Gynecol. 2005; 106:965-72.

10. Karmon A, Sheiner E. Timing of gestation after bariatric surgery: should women delay pregnancy for at least 1 postoperative year? Am J Perinatol. 2008; 25:331-3.

11. Maggard MA, Yermilov I, Li Z, et al. Pregnancy and fertility following bariatric surgery: a systematic review. JAMA. 2008; 300:2286-96. 
12. Sheiner E, Balaban E, Dreiher J, Levi I, Levy A. Pregnancy outcome in patients following different types of bariatric surgeries. Obes Surg. 2009; 19:1286-92.

13. Wax JR, Cartin A, Wolff R, Lepich S, Pinette MG, Blackstone J. Pregnancy following gastric bypass surgery for morbid obesity: maternal and neonatal outcomes. Obes Surg. $2008 ; 18: 540-4$

14. Guelinckx I, Devlieger R, Vansant G. Reproductive outcome after bariatric surgery: a critical review. Hum Reprod Update. 2009; 15:189-201.

15. Ducarme G, Revaux A, Rodrigues A, Aissaoui F, Pharisien I, Uzan M. Obstetric outcome following laparoscopic adjustable gastric banding. Int J Gynaecol Obstet. 2007; 98:244-7.

16. Patel JA, Patel NA, Thomas RL, Nelms JK, Colella JJ. Pregnancy outcomes after laparoscopic Roux-en-Y gastric bypass. Surg Obes Relat Dis. 2008; 4:39-45

17. Centre for Epidemiology, National Board of Health and Welfare. The Swedish Medical Birth Register; A summary of content and quality (Article no. 2003-112-3) (http://www.sos.se/fulltext/112/2003-112-3/2003-112-3.pdf). 2003, National Board of Health and Welfare: Stockholm, Sweden.

18. Statistics Sweden. A new Total Population Register system. More possibilities and better quality. (Serial no. 2002:2). 2002, Statistics Sweden: Örebro, Sweden.

19. Centre for Epidemiology, National Board of Health and Welfare. In-patient diseases in Sweden 1987-2001 (Article no. 2003-42-8) (http://www.sos.se/fulltext/42/2003-428/2003-428.pdf). 2003, National Board of Health and Welfare: Stockholm, Sweden.

20. Centre for Epidemiology, National Board of Health and Welfare. The Swedish version of 8th revision of WHO International Classification of Diseases (http://www.sos.se/epc/klassifi/FILER/KS68.pdf). 1968, National Board of Health and Welfare: Stockholm, Sweden. 
21. Centre for Epidemiology, National Board of Health and Welfare. The Swedish version of 9th revision of WHO's International Classification of Diseases (http://www.sos.se/epc/klassifi/FILER/klass87.pdf). 1987, National Board of Health and Welfare: Stockholm, Sweden.

22. Centre for Epidemiology, National Board of Health and Welfare. The Swedish version of 10th revision of WHO's International Classification of Diseases (http://www.sos.se/epc/klassifi/ksh97kap.htm). 1997, National Board of Health and Welfare: Stockholm, Sweden.

23. Centre of Epidemiology, National Board of Health and Welfare. Causes of Death 2001. (http://www.sos.se/FULLTEXT/42/2003-42-5/2003-42-5.pdf). 2003, National Board of Health and Welfare: Stockholm, Sweden.

24. Statistics Sweden. Multi-generation register 2002; a description of contents and quality (Serial no. 2003:5). 2003, Statistics Sweden: Örebro, Sweden. Statistics Sweden. Population and Housing Census 1970 (SOS). Part 12. Report on the planning and processing of the Population and Housing Census 1970. 1974, National Central Bureau of Statistics: Stockholm, Sweden.

25. Statistics Sweden. Educational Attainment of the Population 2002. (Publication no.UF0506). (http://www.scb.se). 2003, Statistics Sweden: Örebro, Sweden.

26. Statistics Sweden. Population and housing census 1970. Part 13. Economic activity and education. Definitions, comparability, development, etc. 1975, National Central Bureau of Statistics, 1975: Stockholm, Sweden.

27. K. Marsal K, Persson PH, Larsen T, Lilja H, Selbing A, Sultan B. Intrauterine growth curves based on ultrasonically estimated foetal weights. Acta Paediatr. 1996; 85: 843-8. 
28. Bennett WL, Gilson MM, Jamshidi R, Burke AE, Segal JB, Steele KE, Makary MA, Clark JM. Impact of bariatric surgery on hypertensive disorders in pregnancy: retrospective analysis of insurance claims data. BMJ 2010; 340: c1662.

29. ACOG. ACOG Committee Opinion number 315, September 2005. Obesity in pregnancy. Obstet Gynecol. 2005; 106:671-5.

30. Wax JR, Cartin A, Wolff R, Lepich S, Pinette MG, Blackstone J. Pregnancy following gastric bypass for morbid obesity: effect of surgery-to-conception interval on maternal and neonatal outcomes. Obes Surg. 2008; 18:1517-21.

31. Linne Y, Rossner S. Interrelationships between weight development and weight retention in subsequent pregnancies: the SPAWN study. Acta Obstet Gynecol Scand. 2003; 82:318325. 
Table 1. Sociodemographic characteristics of the parents to all women in the study cohort

Gastric surgery

No

Yes

Mother's educational level

Missing\$

9-10 years

$11-13$ years

$\geq 14$ years

\begin{tabular}{crrrr}
$\mathbf{n}$ & \% & \multicolumn{1}{c}{$\mathbf{n}$} & $\mathbf{\%}$ & $\mathbf{p}$ \\
32,756 & 6.6 & 51 & 7.5 & $<0.001$ \\
141,250 & 28.6 & 293 & 43.0 & \\
208,397 & 42.2 & 294 & 43.2 & \\
111,608 & 22.6 & 43 & 6.3 &
\end{tabular}

Father's educational level

\section{Missing\$}

9-10 years

11-13 years

$\geq 14$ years

Mother's marital status

Married

Divorced/widow

Unmarried

\section{Mother's age}

13-19 years

20-26 years

27-33 years

$\geq 34$ years

Mother's parity

No previous children

Previous children

\section{Parent's country of origin}

Both Nordic

One or both non-Nordic

$\begin{array}{rrrrr}36,969 & 7.5 & 56 & 8.2 & <0.001 \\ 155,825 & 31.5 & 312 & 45.8 & \\ 196,704 & 39.8 & 273 & 40.1 & \\ 104,513 & 21.2 & 40 & 5.9 & \end{array}$

$\begin{array}{rrrrr}342,504 & 69.3 & 414 & 60.8 & <0.001 \\ 134,254 & 27.2 & 229 & 33.6 & \\ 17,253 & 3.5 & 38 & 5.6 & \end{array}$

$\begin{array}{rrrrr}27,492 & 5.6 & 90 & 13.2 & <0.001 \\ 218,438 & 44.2 & 333 & 48.9 & \\ 197,996 & 40.1 & 196 & 28.8 & \\ 50,085 & 10.1 & 62 & 9.1 & \end{array}$

$\begin{array}{llll}209,644 & 42.4 & 272 & 39.9 \\ 284,367 & 57.6 & 409 & 60.1\end{array}$

0.188

$\begin{array}{lllll}455,859 & 92.3 & 634 & 93.1 & 0.422\end{array}$

$\begin{array}{llll}38,152 & 7.7 & 47 & 6.9\end{array}$


Table 2. Obstetric outcome of all studied women's own births in 1973-1983.

\begin{tabular}{|c|c|c|c|c|c|}
\hline \multicolumn{6}{|c|}{ Bariatric surgery } \\
\hline & \multicolumn{2}{|c|}{ No } & \multicolumn{2}{|c|}{ Yes } & \multirow[b]{2}{*}{$\mathbf{p}$} \\
\hline & $\mathbf{n}$ & $\%$ & $\mathbf{n}$ & $\%$ & \\
\hline Gestational length (mean/SD) & 39.7 & 1.8 & 39.7 & 1.9 & 0.812 \\
\hline Birth weight (mean/SD) & $3,429.7$ & 520.8 & $3,484.3$ & 582.7 & 0.006 \\
\hline \multicolumn{6}{|l|}{ Born preterm } \\
\hline No & 472,216 & 95.6 & 643 & 94.4 & 0.138 \\
\hline Yes & 21,795 & 4.4 & 38 & 5.6 & \\
\hline \multicolumn{6}{|l|}{ Born SGA } \\
\hline No & 475,398 & 96.2 & 653 & 95.9 & 0.638 \\
\hline Yes & 18,613 & 3.8 & 28 & 4.1 & \\
\hline \multicolumn{6}{|l|}{ Born LGA } \\
\hline No & 482,150 & 97.6 & 653 & 95.9 & 0.004 \\
\hline Yes & 11,861 & 2.4 & 28 & 4.1 & \\
\hline \multicolumn{6}{|l|}{ Twin birth } \\
\hline No & 485,677 & 98.3 & 669 & 98.2 & 0.879 \\
\hline Yes & 8,334 & 1.7 & 12 & 1.8 & \\
\hline \multicolumn{6}{|l|}{ Normal delivery } \\
\hline No & 150,825 & 30.5 & 189 & 28.4 & 0.238 \\
\hline Yes & 343,202 & 69.5 & 476 & 71.6 & \\
\hline \multicolumn{6}{|l|}{ Instrumental delivery } \\
\hline No & 469,153 & 95.0 & 655 & 96.2 & 0.148 \\
\hline Yes & 24,858 & 5.0 & 26 & 3.8 & \\
\hline \multicolumn{6}{|l|}{ Cesarean section } \\
\hline No & 447,202 & 90.5 & 614 & 90.2 & 0.746 \\
\hline Yes & 46,809 & 9.5 & 67 & 9.8 & \\
\hline
\end{tabular}


Table 3. Sociodemographic characteristics as well as BMI, smoking prevalence of hypertension/preeclampsia and diabetes at the time of all studied women's own pregnancies.

\begin{tabular}{|c|c|c|c|c|c|c|c|}
\hline \multicolumn{8}{|c|}{ Bariatric surgery } \\
\hline & \multicolumn{2}{|c|}{ No } & \multicolumn{2}{|c|}{$\begin{array}{l}\text { Yes, before } \\
\text { first child }\end{array}$} & \multicolumn{2}{|c|}{$\begin{array}{l}\text { Yes, after } \\
\text { first child }\end{array}$} & \multirow[b]{2}{*}{$\mathbf{p}$} \\
\hline & $\mathbf{n}$ & $\%$ & $\mathbf{n}$ & $\%$ & $\mathbf{n}$ & $\%$ & \\
\hline Age & & & & & & & $0.541^{1}$ \\
\hline $13-19$ years & 8,198 & 4.3 & 3 & 3.3 & 36 & 14.9 & $<0.001^{2}$ \\
\hline 20-24 years & 55,439 & 29.4 & 39 & 32.3 & 103 & 42.7 & $<0.001^{3}$ \\
\hline$\geq 25$ years & 124,863 & 66.2 & 84 & 64.5 & 102 & 42.3 & \\
\hline Educational level & & & & & & & $<0.001^{1}$ \\
\hline $9-10$ years & 23,994 & 127 & 45 & 35.7 & 76 & 31.5 & $<0.001^{2}$ \\
\hline $11-13$ years & 104,805 & 55.6 & 78 & 61.9 & 149 & 61.8 & $0.310^{3}$ \\
\hline$\geq 14$ years & 58,539 & 31.1 & 3 & 2.4 & 14 & 5.8 & \\
\hline \$Missing & 1,162 & 0.6 & 0 & 0.0 & 2 & 0.8 & \\
\hline Cohabitation status & & & & & & & $0.003^{1}$ \\
\hline Living with the child's father & 165,716 & 87.9 & 100 & 79.4 & 185 & 76,8 & $<0.001^{2}$ \\
\hline Other family situation & 22,784 & 12.1 & 26 & 20.1 & 56 & 23,2 & $0.570^{3}$ \\
\hline Smoking habits & & & & & & & $<0.001^{1}$ \\
\hline Not smoking & 165886 & 88.0 & 83 & 65.9 & 174 & 72.2 & $<0.001^{2}$ \\
\hline Smoking & 22,614 & 12.0 & 43 & 34.1 & 67 & 27.8 & $0.209^{3}$ \\
\hline BMI & & & & & & & $<0.001^{1}$ \\
\hline$<24.9$ & 107,807 & 57.2 & 5 & 4.0 & 6 & 2.5 & $<0.001^{2}$ \\
\hline $25-29.9$ & 37,768 & 20.0 & 28 & 22.2 & 21 & 8.7 & $<0.001^{3}$ \\
\hline $30-34.9$ & 11,988 & 6.4 & 37 & 29.4 & 55 & 22.8 & \\
\hline $35-39.9$ & 3,821 & 2,0 & 24 & 19.0 & 55 & 22.8 & \\
\hline$\geq 40$ & 1,281 & 0.7 & 11 & 8.7 & 54 & 22.4 & \\
\hline \$Missing & 25,835 & 13.7 & 21 & 16.7 & 50 & 20.7 & \\
\hline Hypertension/Pre-eclampsia & & & & & & & $0.593^{1}$ \\
\hline No & 186,442 & 98.9 & 124 & 98.4 & 235 & 97.5 & $0.037^{2}$ \\
\hline Yes & 2,058 & 1.1 & 2 & 1.6 & 6 & 2.5 & $0.574^{3}$ \\
\hline Diabetes & & & & & & & $0.568^{1}$ \\
\hline No & 187,648 & 99.5 & 125 & 99.2 & 238 & 98.8 & $0.067^{2}$ \\
\hline Yes & 852 & 0.5 & 1 & 0.8 & 3 & 1.2 & $0.693^{3}$ \\
\hline
\end{tabular}

1 Comparison between "no surgery" and "surgery before first child"

2 Comparison between "no surgery" and "surgery after first child"

3 Comparison between "surgery before first child" and "surgery after first child" 
Table 4. Obstetric outcome of all studied women's first child.

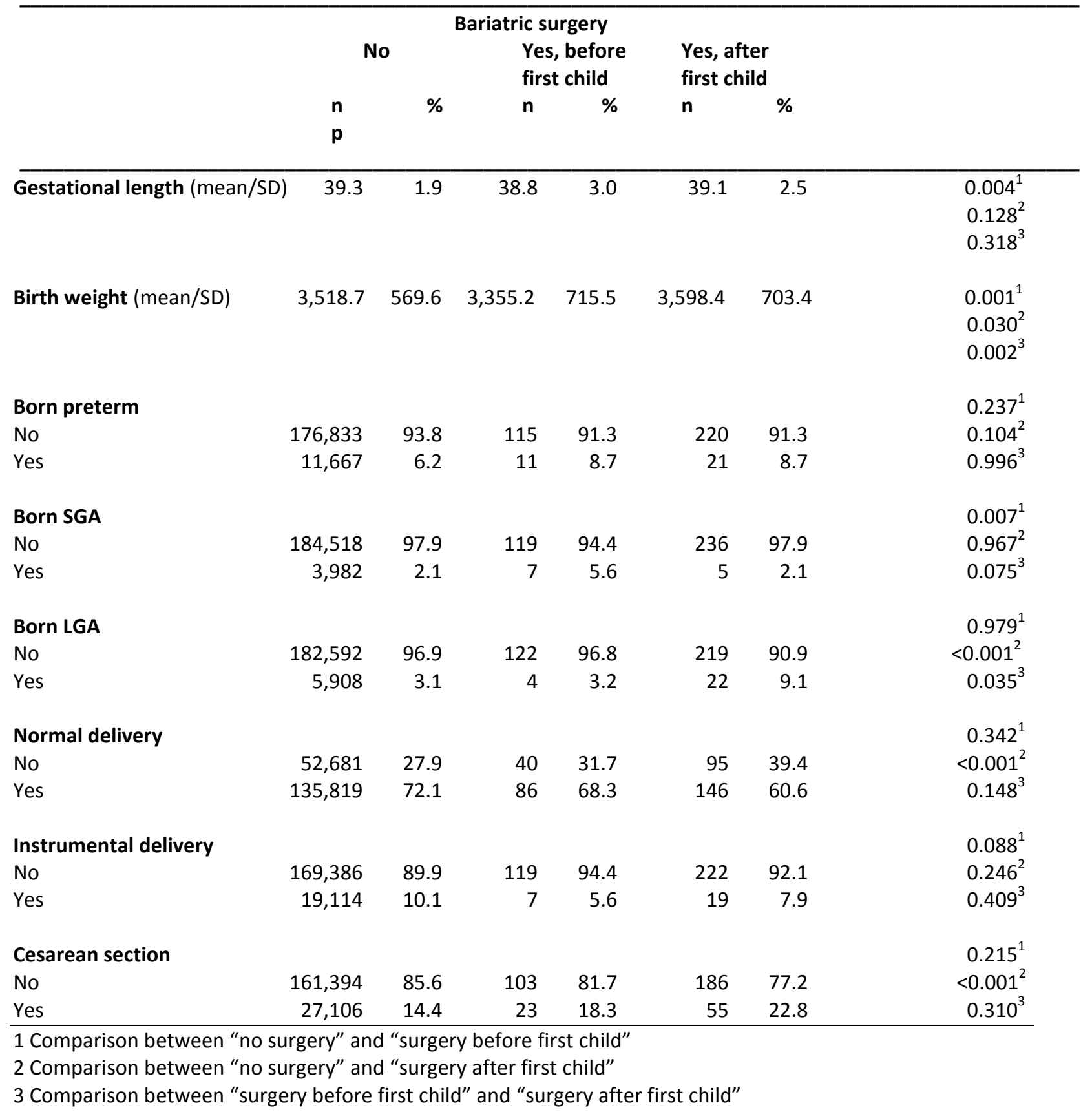

